Conf- $910869--23$

GA-A206950ST

\title{
MODELING OF FAST WAVE CURRENT DRIVE EXPERIMENTS ON DIII-D
}

by

T.C. LUCE, S.C. CHIU, R.W. HARVEY, M.J. MAYBERRY,

C.C. PETTY, R.I. PINSKER, R. PRATER and S.I. TSUNODA

SEPTEMBER 1991

\section{GENERAL ATOMICS}




\section{DISCLAIMER}

This report was prepared as an account of work sponsored by an agency of the United States Government. Neither the United States Government nor any agency thereof, nor any of their employees, makes any warranty, express or implied, or asoumes any legal liaivility or responsibility for the accuracy, completeness, or usefulness of any information, apparatus, product, or process disclosed, or represents that its use would not infringe privately owned rights. Reference herein to any specific commercial product, process, or service by trade name, trademark, manufacturer, or otherwise, does not necessarily constitute or imply its endorsement, recommendation, or favoring by the United States Government or any agency thereof. The views and opinions of authors expressed herein do not necesaarily state or reflect those of the United States Government or any agency thereof. 


\title{
MODELING OF FAST WAVE CURRENT DRIVE EXPERIMENTS ON DIII-D
}

\author{
by \\ T.C. LUCE, S.C. CHIU, R.W. HARVEY, M.J. MAYBERRY, \\ C.C. PETTY, R.I. PINSKER, R. PRATER and S.I. TSUNODA
}

This is a preprint of a paper to be presented at the Ninth Topical Conference on the Radio Frequency, August 19-21, 1991, in Charleston, South Carolina, and to be printed in the Proceedings.

Work supported by

U.S. Department of Energy

Contract DE-AC03-89ER51114

\section{GENERAL ATOMICS PROJECT 3466 SEPTEMBER 1991}

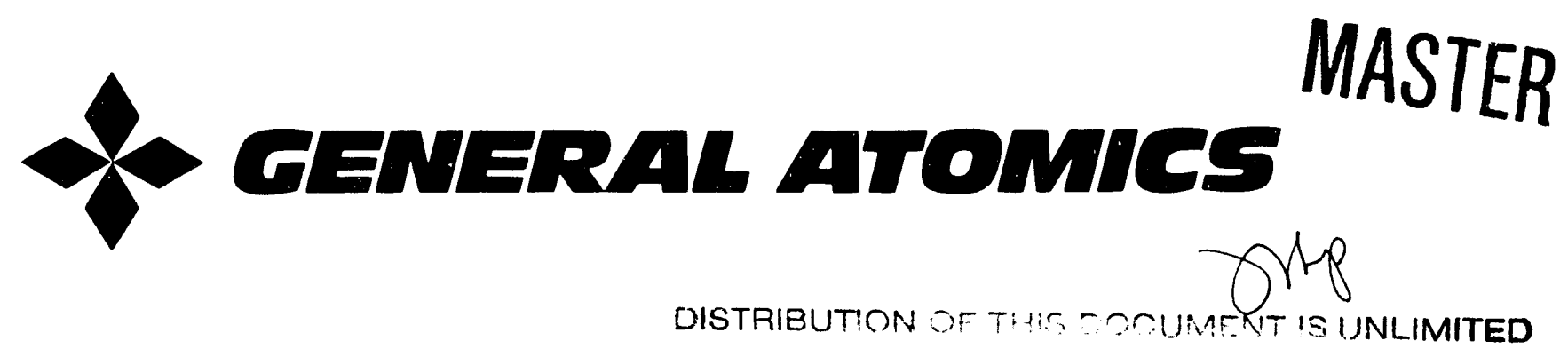




\title{
Modeling of Fast Wave Current Drive Experiments on DIII-D
}

\author{
T.C. Luce, S.C. Chiu, R.W. Harvey, M.J. Mayberry, C.C. Petty \\ R.I. Pinsker, R. Prater, and S.I. Tsunoda
}

General Atomics, P.O. Box 85608, San Diego, California 92138-5608

\begin{abstract}
Modeling of fast wave current drive experiments for DIII-D has been improved to include calculation of target temperature profiles consistent with the DIII-D database and more accurate modeling of the launched spectrum. The calculations indicate that a measurable current will be driven by fast waves in the near-term (30-200 kA). Modeling of the long-range goal of $2 \mathrm{MA}$ non-inductive at high $\beta$ indicates the proposed $18 \mathrm{MW}$ of If power will be adequate. The optimum frequency for the intermediate scenario is $120 \mathrm{MHz}$; this frequency selection is also adequate for the long-term goals.
\end{abstract}

Significant advancements in modeling fast wave current drive (FWCD) scenarios for DIII-D have been made since the last if conference [1]. The present plan for FWCD employs electron cyclotron heating (ECH) to provide high electron temperature and some non-inductive current. Previously, driven current in arbitrary density and temperature profiles was calculated for a single $n_{\|}$in slab geometry. The modeling is now carried out in the DIII-D flux geometry with kinetic profiles consistent with the ECH experimental database. Furthermore, the antenna spectrum is modeled by a set of discrete rays rather than a single $n_{\|}$.

The temperature profiles are calculated with the ONETWO transport code [2] which solves the radial power balance. The electron density and $\mathrm{Z}_{\text {eff }}$ profiles are specified and are fixed in time. The ion densities (including a minority species if desired) are determined from these input parameters. The transport code evolves $T_{e}, T_{i}$, and $J$ self-consistently for given transport coefficients, neoclassical resistivity and calculated Ohmic, ECH, and FW deposition profiles. The transport coefficients $\kappa_{e}$ and $\kappa_{i}$ are chosen to give stored energy consistent with the ITERP-89 confinement scaling for L-mode plasmas and the DIII-D empirical scaling for ELMing H-mode plasmas. The ITERP-89 scaling relation fits the existing ECH confinement database very well [3]. The spatial dependence of $\kappa_{e}$ is constant, while $\kappa_{i}$ is a constart multiple of the neoclassical value. The values of $\kappa_{e}$ and $\kappa_{i}$ are chosen such that $\kappa_{i} \lesssim \kappa_{e}$. The ECH deposition profile and driven current profile are calculated by the TORAY ray-tracing code [4]. Bootstrap current is calculated using the Hirshman-Sigmar formulation. Sawtooth effects are also taken into account by forcing a Kadomtsev-type rearrangement of $\mathrm{T}_{e}$ and $\mathrm{J}$ when $q(0)=$ 0.8 .

The FW absorption and current drive are calculated with a modified version of the slab model used previously $[1,5]$. The wave propagation is modeled by straightline rays in the major radial direction with $n_{\|} R$ constant. The rays are mapped onto the magnetic flux coordinates to correctly account for heat deposition, current profile, and trapping effects. The heating and current deposition are spread in the vertical direction using a width consistent with full-wave calculations. This does not affect the total absorbed power or driven current, only its location. Only single-pass absorption is included in the model. The antenna spectrum is modeled by up to 20 discrete rays. The propagating spectrum in $n_{\|}$is calculated by Fourier analysis of the antenna geometry and an accounting for the evanescence layer between the fast wave cut-off in the edge and the antenna. The effects of reflections from the edge density gradient and image currents in the sipta between the antenna straps are not included. 
There are several effects not included in the model which may be important. Recent direct electron heating experiments with symmetric spectra find confinement consistent with full absorption, probably due to multiple passes [6]. It is not yet clear that the waves will retain the appropriate $n_{\|}$and reasonable directionality with current drive phasing. Therefore, only single-pass absorption is calculated. Previous electron cyclotron current drive (ECCD) experiments on DIII-D pointed out the strong effect on the current drive efficiency of the remaining Ohmic electric field [7], even at fields much lower than the Dreicer field. Enhancements of 2-3 were observed. The modeling reported here does not have a self-consistent correction to the efficiency for the calculated electric field. The assumption of straight-line rays with $n_{\|} R$ constant does not allow any ray tracing effects such as refraction away from the center or enhanced $n_{\|}$upshifts. Finally, there is no modeling of any synergistic velocity space effects between the ECH and FW. All of these effects, with the possible exception of ray tracing, should be favorable to current drive; therefore, the current drive estimates given here are conservative.

The near-term scenario for FWCD experiments involves $1.3 \mathrm{MW} \mathrm{ECH}$ at $60 \mathrm{GHz}$ and $1.8 \mathrm{MW} \mathrm{FW}$ at $60 \mathrm{MHz}$. These are the maximum power levels expected. The plasmas will be intentionally held in L-mode to avoid the density increase associated with H-mode. Table 1 gives the relevant parameters for one choice of $I$ and $\bar{n}$. Systematic scans of machine parameters indicate that maximizing single-pass absorption does not necessarily maximize $I_{F w}$. The unifying parameter for this data is found to be central electron temperature. Figure 1 shows that the FWCD is a monotonic function of $T_{e}(0)$ within the constraints of this model and the present operating boundaries of DIII-D. The lack of correlation of $\mathrm{I}_{\mathrm{FW}}$ with single-pass absorption is a consequence of the fact that the peak I/P as a function of $n_{\|}$does not correspond with the peak absorption, due to the strong increase in current drive efficiency with decreasing $n_{\|}$. Depending on the exact operating conditions and power available during the experiments, the FWCD should be in the range 30-200 kA in the near-term. Again, these estimates are conservative, but they indicate that a physics study of FWCD is feasible.

One of the long-range goals of the DIII-D tokmak is to demonstrate complete non-inductive current drive at high beta. The present plan includes $10 \mathrm{MW}$ of ECH at $110 \mathrm{GHz}$ and $4 \mathrm{MW}$ of $\mathrm{FW}$ at both $60 \mathrm{MHz}$ and $120 \mathrm{MHz}$. Confinement quality must be $\mathrm{H}$-mode to obtain both high $\beta$ and the high temperatures required for efficient current drive. Table 2 gives the relevant plasma parameters for an intermediate scenario, which demonstrates $1 \mathrm{MA}$ non-inductive, and the long-range scenario for $2 \mathrm{MA}$. Neutral beams will be added in the final scenario to take the plasma to the $\beta$ limit. Note that the ion absorption is relatively small, even with a $5 \%$ hydrogen minority. The crucial hurdle to be cleared for these scenarios is implementation of effective density control during $\mathrm{H}$-mode. The Advanced Divertor Program carried on by General Atomics and collaborators is making progress toward this goal [8].

The choice of frequency for the FW in the intermediate scenario is an important issue. An optimization study from $60 \mathrm{MHz}$ to $200 \mathrm{MHz}$ was carried out for the plasma conditions simulated in the intermediate case and a fixed antenna (6 straps, $90^{\circ}$ phasing). The plasma profiles were fixed, so self-consistent heating effects were neglected. The study indicated that $120 \mathrm{MHz}$ was the optimum frequency under these conditions with a net I/P of $0.074 \mathrm{~A} / \mathrm{W}$. There are two physics issues which determine the frequency choice. First, the absorption scales like $k_{\perp}$ which is approximately $\omega / v_{A}$. As the frequency increases, the single-pass $I / P$ increases at all $n_{\|}$(see Fig. 2.). The second effect is the matching of the antenna $n_{\|}$spectrum to the peak of $I / P$. For a given antenna, an increase in $\omega$ decreases $n_{\|}$. As shown in Fig. 2, the spectrum for $60 \mathrm{MHz}$ is too slow ( $n_{\|}$is too high), while the spectrum for $200 \mathrm{MHz}$ is too fast $\left(n_{\|}\right.$is too low). The spectrum at $120 \mathrm{MHz}$ is well matched to the predicted plasma conditions. Since the target conditions are calculated for maximum performance, a flexible system 
for $60-120 \mathrm{MHz}$ is be optimal for the period up to the intermediate case. In the long term, the simulation described in Table 2 indicates that this system would still be suitable to achieve the long-term goal, although at these temperatures it is no longer optimized.

In summary, the present FWCD modeling capabilities indicate that measurable FW current can be driven in the near-term, which will allow investigation of issues such as multiple-pass current drive and ray tracing effects. The combined systems for ECH and FWCD proposed for DIII-D appear adequate to demonstrate non-inductive current drive at high $\beta$ and $2 \mathrm{MA}$ with an intermediate step at $1 \mathrm{MA}$.

\section{ACKNOWLEDGMENT}

This work was supported by the U.S. Department of Energy under Contract No. DE-AC03-89ER51114.

\section{REFERENCES}

[1] M.J. Mayberry, et al., Proc. AIP Conf. 190, 298 (1989).

[2] W.W. Pfeiffer, etal, "ONETWO: A Computer Code for Modeling Plasma Transport in Tokamaks," GA Report GA-A16178 (1980).

[3] T.C. Luce, et al., in Plasma Physics and Controlled Nuclear Fusion Research (Proc. 13th Int. C`nf. Washington, D.C., 1990) Vol. I, IAEA, p. 631.

[4] K. Matsuda, IEEE Trans. Plas. Sci. 17, 6 (1989); A.H. Kritz, et al., Proc. $3^{\text {rd }}$ Joint Varenna-Grenoble Intn 1. Symp. on Heating in Toroidal Plasmas (Gernoble, France; EURATOM rep. EUR 70070EN, 1980) Vol. II, p 707.

[5] S.S. Chiu, et al., Nucl. Fusion 29, 2175 (1989).

[6] C.C. Petty, et al., these proceedings.

[7] R.A. James, et al., in Plasmas Physics and Cont. Fusion (Proc. 17 th EPS Conf., Amsterdam) Pt III, p. 1259 (1990); R.A. James, et al., "Electron Cyclotron Current Drive Experiments in the DIII-D Tokamak," GA Report GA-A20429 (1991), submitted to Phys. Rev. Lett.

[8] M.A. Mahdavi, et al., in Plasma Physics and Controlled Nuclear Fusion Research (Proc. 13th Int. Conf. Washington, D.C., 1990) Vol. I, IAEA, p. 335.

TABLE 1

$\begin{array}{ll}B & 1.09 \mathrm{~T} \\ I & 0.6 \mathrm{MA} \\ \bar{n} & 1 \times 10^{13} \mathrm{~cm}^{-3} \\ P_{E C H}(60 \mathrm{GHz}) & 1.3 \mathrm{MW} \\ P_{F W}\left(60 \mathrm{MHz}, \Delta \phi=90^{\circ}\right) & 1.8 \mathrm{MW} \\ T_{e}(0) & 3.8 \mathrm{keV} \\ Z_{A} & 1.5 \\ \tau_{E} & 75 \mathrm{msec} \\ I_{\text {FwCD }} & 74 \mathrm{kA} \\ I_{\text {ECCD }} & 84 \mathrm{kA} \\ \text { IBS }_{\text {BS }} & 85 \mathrm{kA} \\ I_{\text {Nos-inductio }} & 243 \mathrm{kA} \\ \text { Fraction non-inductive current } & 41 \% \\ \text { Fraction FW absorbed } & 19.7 \%\end{array}$

TABLE 2

Simulation of Intermediste and Long-Range Scenario

\begin{tabular}{|c|c|c|}
\hline & Intermodinte & Long-Range \\
\hline $\mathbf{B}$ & $2.03 \mathrm{~T}$ & $1.85 \mathrm{~T}$ \\
\hline I & $1.0 \mathrm{MA}$ & $2.0 \mathrm{MA}$ \\
\hline n & $4 \times 10^{13} \mathrm{~cm}^{-3}$ & $4 \times 10^{13} \mathrm{~cm}^{-3}$ \\
\hline Pech $(110 \mathrm{GHz})$ & $7 \mathrm{MW}$ & $10 \mathrm{MW}$ \\
\hline$P_{\text {pw }}(60 \mathrm{MHz}, 120 \mathrm{MHz})$ & $2 M W$ each & $4 M W$ each \\
\hline$T_{*}(0)$ & $10.8 \mathrm{keV}$ & $27 \mathrm{keV}$ \\
\hline$z_{n+\pi}$ & 1.5 & 1.5 \\
\hline $\mathbf{r}$ & $104 \mathrm{mesc}$ & 170 misex \\
\hline Irw & $0.20 \mathrm{MA}$ & $1.04 \mathrm{MA}$ \\
\hline $\mathrm{I}_{\mathrm{BCCD}}$ & $0.49 \mathrm{MA}$ & $0.93 \mathrm{MA}$ \\
\hline IBs & $0.36 \mathrm{MA}$ & $0.59 \mathrm{MA}$ \\
\hline IOH & $-0.05 \mathrm{MA}$ & $-0.56 \mathrm{MA}$ \\
\hline \multicolumn{3}{|l|}{ Fraction power abeorbed } \\
\hline $\begin{array}{l}60 \mathrm{MH} \\
120 \mathrm{MH}\end{array}$ & $\begin{array}{l}38.1 \% \text { (electrons) } \\
9.3 \% \text { (iuns, } 5 \% \mathrm{H} \text { ) } \\
51.0 \%\end{array}$ & $\begin{array}{l}75.6 \% \text { (electrons) } \\
5.2 \% \text { (ions, } 5 \% \mathrm{H} \text { ) } \\
89.8 \% \text { (electrons) }\end{array}$ \\
\hline$\beta$ & $1.3 \%$ & $3.8 \%$ \\
\hline$\beta_{\mathrm{N}}$ & 1.6 & 2.1 \\
\hline
\end{tabular}




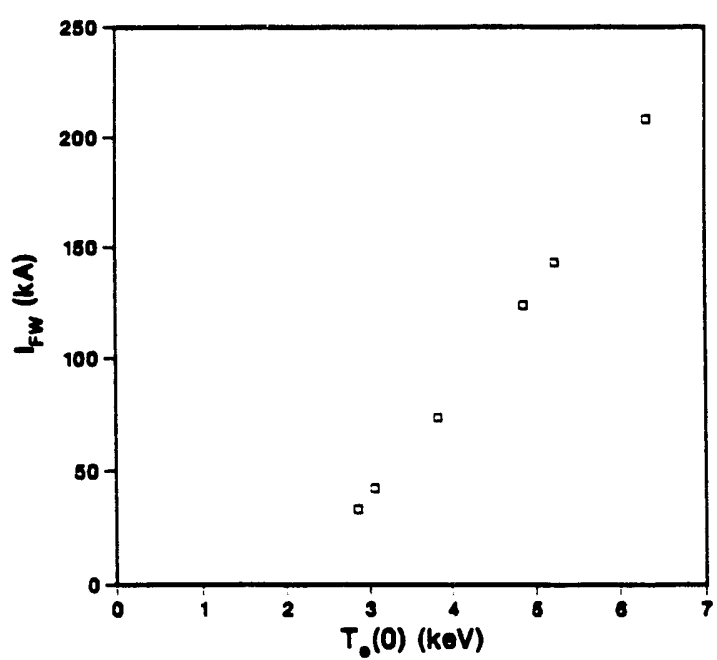

Fig. 1. Single-pass FWCD versus central electron temperature.

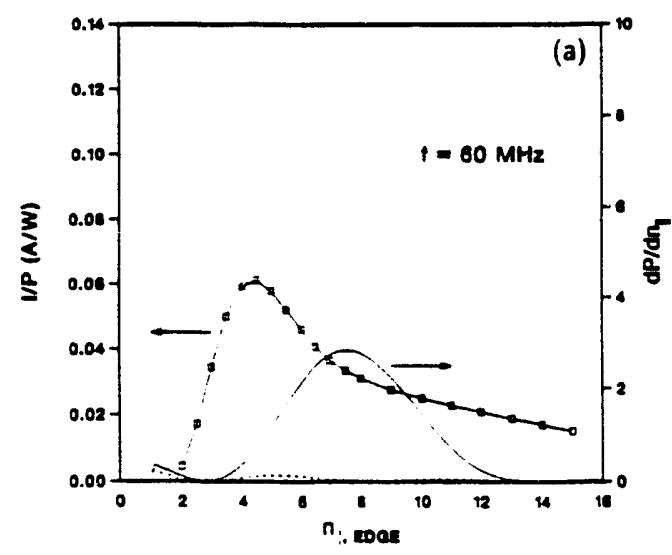

Fig. 2. Comparison of $1 / P$ and $d P / d n_{\|}$for (a) 60, (b) 120, and (c) $200 \mathrm{MHz}$ for fixed plasma conditions and antenna. The dashed lines represent $\mathrm{dP} / \mathrm{d} n_{\|}$for $n_{\|}<0$.
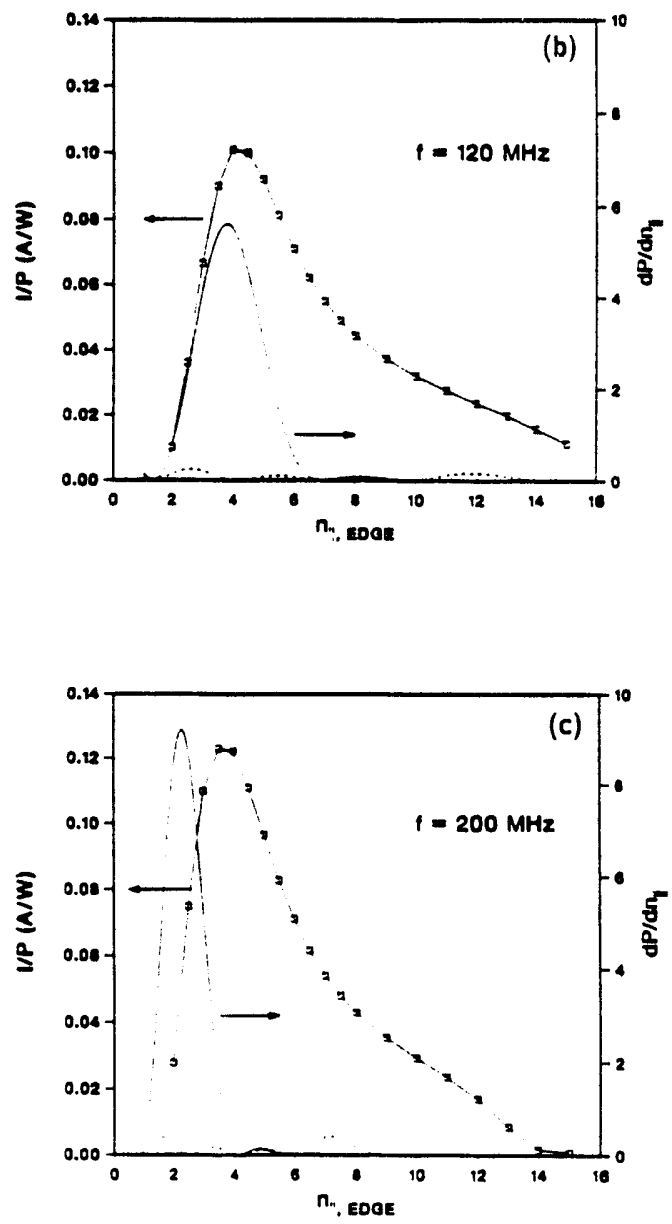

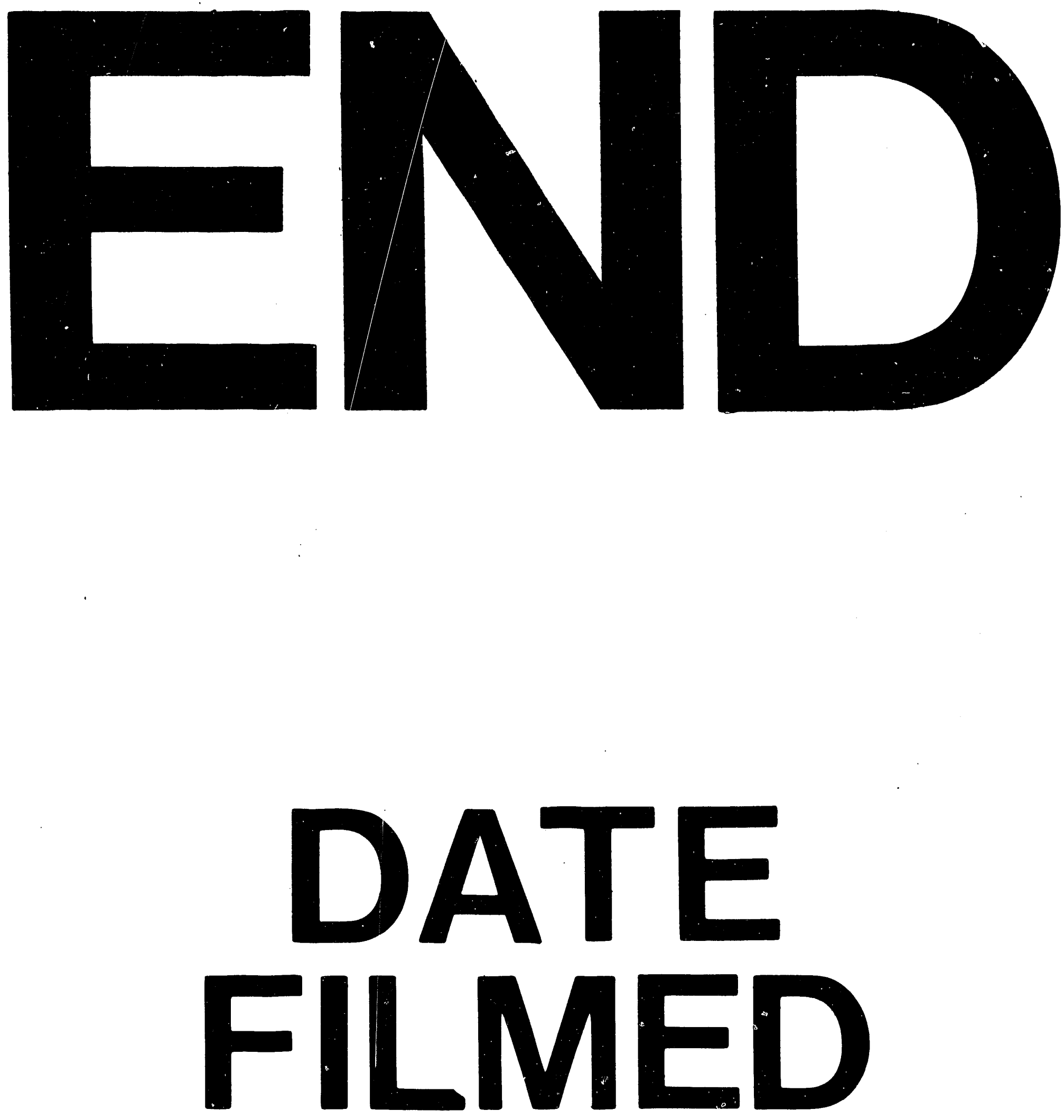

1

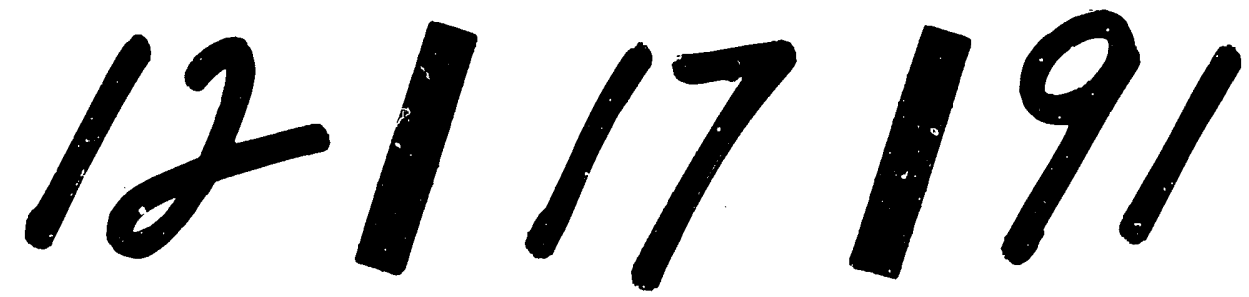


(2) 